Ilinca, S., Hamer, S., Botje, D., Espin, J., Veloso Mendes, R., Mueller, J., Wijngaarden, J. van, Vinot, D., Plochg, T. All you need to know about innovation in healthcare: the 10 best reads. International Journal of Healthcare Management: 2012, 5(4), 193-202

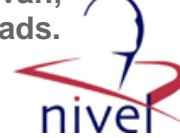

\begin{tabular}{|l|l|}
\hline $\begin{array}{l}\text { Postprint } \\
\text { Version }\end{array}$ & 1.0 \\
\hline Journal website & $\underline{\text { http://www.ingentaconnect.com/content/maney/ihm/2012/00000005/00000004/ar }}$ \\
\hline Pubmed link & $\underline{\text { 00003 }}$ \\
\hline DOI & $10.1179 / 2047971912$ Y.0000000018 \\
\hline
\end{tabular}

This is a NIVEL certified Post Print, more info at http://www.nivel.eu

\title{
All you need to know about innovation in healthcare: The 10 best reads
}

STEFANIA ILINCA ${ }^{1}$, SUSAN HAMER ${ }^{2}$, DAAN BOTJE ${ }^{3}$, JAIME ESPIN ${ }^{4}$, RITA VELOSO MENDES ${ }^{5}$, JANI MUELLER ${ }^{6}$, JEROEN VAN WIJNGAARDEN ${ }^{7}$, DiDIER VINOT ${ }^{8}$, THOMAS PLOCHG $^{9}$

${ }^{1}$ Institute of Economics, Universita della Svizzera italiana, Lugano,

Switzerland

${ }^{2}$ National Institute for Health Research - Clinical Research Network, Leeds, UK

${ }^{3}$ NIVEL Netherlands Institute for Health Services Research, Utrecht, the Netherlands

${ }^{4}$ Andalusian School of Public Health, Campus Universtario de Cartuja, Granada, Spain

${ }^{5}$ CIES-IUL, Avenida das Forças Armadas, Edíficio ISCTE, Lisboa, Portugal ${ }^{6}$ University of the Witwatersrand, Johannesburg, South Africa

${ }^{7}$ Institute of Health Policy and Management, Erasmus University Rotterdam, Rotterdam, the Netherlands

${ }^{8}$ IFROSS - Institute for Training and Research in Health Management, Université Jean Moulin Lyon 3, Lyon, France

${ }^{9}$ Department of Public Health, Academic Medical Center/University of Amsterdam, Amsterdam, the Netherlands

\begin{abstract}
Drawing on the vast extant literature on innovation, we propose a top 10 of best reads all healthcare managers should familiarize themselves with. A Delphi study has been conducted to identify and select the 10 most relevant and informative scientific writings, which can add significantly to the knowledge ofmanagers by offering an introduction in the academic discussion on this topic. Our must-read list provides a broad but still meaningful overview, which aims for generalizability but maintains a level of precision which can generate clear, implementable ideas; it is a mix between a theory and conceptualization of innovation and practical evidence and advice. We distinguish between four main dimensions of innovation in healthcare: the why, the what, the how, and the
\end{abstract}


Ilinca, S., Hamer, S., Botje, D., Espin, J., Veloso Mendes, R., Mueller, J., Wijngaarden, J. van, Vinot, D., Plochg, T. All you need to know about innovation in healthcare: the 10 best reads. International Journal of Healthcare Management: 2012, 5(4), 193-202

who. While fairly comprehensive in itself, for those interested our list can also constitute a stepping stone towards the more technical academic analyses on innovation processes and dynamics.

\section{BACKGROUND AND RELEVANCE}

In recent years, the healthcare sector has been subject to rapid change in an effort to address and anticipate pressing problems. It is broadly acknowledged that healthcare systems are unsustainable in the long run due to the epidemic of chronic diseases and multi-morbidity,,${ }^{1}{ }^{3}$ fast technological progress, increasing social pressures, tighter financial constraints.

${ }^{4,5}$ The ultimate challenge is improving health system performance while using less financial and human resources. For these reasons, innovation seems critical for the future sustainability of European healthcare systems.

An innovation can be defined as 'an idea, practice, or object that is perceived as new by an individual or other unit of adoption'. 6 It is distinct from invention in that the novelty does not have to be objective, but only perceived, and, for the purpose of the present study, can refer both, to a technological advancement or to a managerial intervention leading to new processes. But while dealing with the 'new', innovation itself is perhaps as old as society and has certainly played a crucial role in its development. Studies of innovation processes are, however, much more recent, and only in the last few decades have entered the mainstream of economic and managerial thinking.

The European policy agenda reflects the growing importance of innovation in 'tackling major societal challenges' and places the creation of the Innovation Union at the centre of its development strategy. ${ }^{7}$ A vast academic literature on the topic also reveals its priority status. This is roughly illustrated by a quick search for 'innovation' in PubMed, one of the most comprehensive bibliographic databases of life sciences and biomedical information. The search yielded 47472 results. When adding 'healthcare' to 'innovation' we obtained 16256 results. Despite progress in innovation studies and the prolific writings of scholars the produced knowledge is inconclusive and difficult to translate into practice. Part of the problem relates to limited availability and accessibility of literature: healthcare managers find it difficult to access, read, and utilize this scientific information. Moreover, dissemination channels are few and inefficient. Apart from that the scientific writings are generally theoretical and abstract, which contrasts with the more hands-on style of managers in need of practical advice and prescriptions. To further complicate matters, the scholarly discourse on innovations has developed in 'siloed production lines'.

Research disciplines like the management sciences, sociology, quality of care, health services research have all developed their isolated knowledge bases; interdisciplinary communications and collaborations have always been the exception rather than the norm. ${ }^{8}$ Against this background, it was timely and relevant to pull together the different strands of literature into a unified, multi-disciplinary overview. As innovation studies have been developed in parallel in various research traditions, the concept means different things to different researchers and the key learnings on innovation relevant for healthcare managers are scattered across disciplinary fields; in other words a panoramic overview is missing. The challenge is to review the extant literature and extract the essence of the existing knowledge on the topic. 
Ilinca, S., Hamer, S., Botje, D., Espin, J., Veloso Mendes, R., Mueller, J., Wijngaarden, J. van, Vinot, D., Plochg, T. All you need to know about innovation in healthcare: the 10 best reads. International Journal of Healthcare Management: 2012, 5(4), 193-202

Thereby, the focus should be on mapping the most significant ideas, essential for understanding and managing successful innovation processes.

The objective of our study was to extract the main messages out of the reported studies and experiences, draw from them the lessons which could prove useful to healthcare managers, and communicate them in an accessible and understandable manner. For this purpose, we conducted a study focusing on identifying, selecting, and highlighting the top 10 most relevant and essential scientific readings on healthcare innovation. The following research question was formulated: What are the top 10 most relevant and essential papers for healthcare managers?

\section{METHODOLOGY}

In order to answer the research question, we conducted a Delphi study. ${ }^{9}$ Our approach diverged somewhat from the classical form in some practical respects most notably participant selection and anonymity preservation. ${ }^{10}$ All experts were selected on the basis of their participation in the European network on medicine and management (see http:// www.dr-in-mgmt.eu). This network, funded by the European Union under the seventh framework, brings together researchers and experts who examine why physicians are drawn into management, and how this impacts on control, user voice, and innovation. The working group on innovation, exploring and conceptualizing the relationship between clinical management and innovation, was a natural pool of experts eligible for participation in the Delphi study. The members of this working group represent universities in six European countries (i.e.

Switzerland, The Netherlands, The United Kingdom, Spain, Finland, and France) and South Africa. Members could participate to the present study as coauthors on a voluntary basis. Their disciplinary fields of expertise ranged from medicine and nursing to management, sociology, public health, and health economics; thus warranting a multi-disciplinary outlook upon the concept of innovation.

By involving such a varied group of scholars, we hope to have provided an enriched perspective on innovation in healthcare which would better respond to the multiple needs of healthcare managers.

We started the data collection process in February 2012 by asking all working group members to create a list of up to 10 scientific writings (i.e. scientific journal papers, books, and reports) on innovation which they considered most important and informative.

Based upon all suggestions an initial list of 48 papers and books was made. Successively, the list was reduced to 40 by eliminating overlaps and all those contributions that were unavailable in English. The 40 titles were made available to all panelists via Dropbox and email.

The structure and scheduling of the Delphi process as well as the criteria to be used in subsequent selection rounds was decided upon by participating experts in a working group meeting in Amsterdam, March 2012. The first round required all participating experts to fill in a questionnaire listing all 40 remaining papers and to rate each of them on the degree of informativeness, importance/relevance, and comprehensibility for healthcare managers. A 5-point Likert scale, anchored at the endpoints, was used throughout the questionnaire, which provided a comments section for any additional remarks and observations. 
Ilinca, S., Hamer, S., Botje, D., Espin, J., Veloso Mendes, R., Mueller, J., Wijngaarden, J. van, Vinot, D., Plochg, T. All you need to know about innovation in healthcare: the 10 best reads. International Journal of Healthcare Management: 2012, 5(4), 193-202

Panel members were instructed to base their assessment on the full text whenever possible, or, failing that on the provided summaries and abstracts. After the collection of results, average and median ratings were calculated for all included papers. The highest rating 21 papers (two papers received equal ratings and could not be differentiated) were selected for the next assessment round. The main purpose of this first voting round was to reduce the list to a more manageable size, which would allow for a more detailed analysis of each contribution.

In the second round participants were asked to carefully read through all the remaining contributions and to rank them in the order of their relevance. A mandatory comments section was included, requiring a concise exposition of the reasons behind the choices and a short statement of what was considered to be the significant contribution of each paper to healthcare managers' knowledge of innovation processes. Based on average and median calculations of the rankings we built a list of 10 papers and books which was resubmitted to the participating experts for assessment, together with a summary of the provided comments.

The thirds and final round was aimed at building consensus around the final format of the list. Panel members were presented with their colleagues' justifications and clarifications on the choices they had made and asked to rethink and revise their position, if they consider it appropriate. Despite not having reached full agreement between members consensus was reached and all concerns raised by group members were addressed in turn.

Numerous criteria have been used for building a taxonomy of innovation processes to name just a few, sectoral groups and flow of knowledge to build classes of innovation modes ${ }^{11}$; innovation strategies and methods to classify European public sector agencies ${ }^{12}$; innovation attributes to differentiate types of innovation in the healthcare setting ${ }^{13}$ - each with their advantages and limitations. Less variation is observed in the classification of the literature on innovation, which is generally organized along disciplinary lines. While this approach has the advantage of facilitating the understanding of the historical development of innovation studies within different theoretical traditions, it also contributes to the fragmentation between them and renders a comprehensive overview difficult.

Based upon our own conceptualization of health innovation in the COST Action working group, ${ }^{14}$ we suggest that the study of innovation, a complex and time consuming effort, should be broken down into more manageable and easily understandable topics, without focusing on any one dimension at the expense of others. In innovation, the most important question to keep in mind is: 'Who wants to innovate what, how and why?'. Borrowing from the journalism concept of the 'five W's ${ }^{15}$ we propose a simple, intuitive classification relying on the four basic questions: - WHY do organizations in healthcare need to innovate? • WHAT is the process through which they innovate? $\bullet$ HOW does innovation take ground and spread? • WHO kindles and drives innovation? In other words, in order to understand the intricacies of innovation in practice and be able to design and implement such processes, a manager must have a clear understanding of the reasons grounding the innovation initiative, the set of procedures and practices that lead to innovation, the drivers and barriers to innovation diffusion, and the roles and idiosyncrasies of the involved actors (Table 1).

These simple questions can prove very useful for managers in organizing the information they access and rendering it contextually relevant. We propose they can 
Ilinca, S., Hamer, S., Botje, D., Espin, J., Veloso Mendes, R., Mueller, J., Wijngaarden, J. van, Vinot, D., Plochg, T. All you need to know about innovation in healthcare: the 10 best reads. International Journal of Healthcare Management: 2012, 5(4), 193-202

be used effectively to make the leap from data and information to structured knowledge that can be easily applied.

While the first three questions have been addressed quite extensively in managerial and business administration studies, the latter has received comparatively less attention. We attempt to fill the gap with insights from the sociology of professions. In the following, we discuss each category in turn. One consideration is essential at this point, the proposed categories are neither rigid nor mutually exclusive. They are interdependent, as the influence of factors at any one level can be felt in all other levels. The papers we propose in our final selection also defy organization into rigid categories and span the boundaries across them. As such, each contribution was listed under the category which best captured its main contribution to the literature and where its insight added most value to the understanding of innovation processes. In recognition of the fact that their importance to the knowledge on innovation is more extensive, we also included a short overview of additional significant topics and ideas presented in the selected papers.

\section{[TABLE 1]}

\section{FINDINGS}

\section{WHY? The purpose of innovation}

As any innovation scholar and any manager who attempted to lead his organization through a change process know, innovation is hard. It is challenging to all those involved and sometimes long, it accrues costs in terms of both financial and human resources before it pays off, and final outcomes are quite difficult to predict with confidence at the onset of the process. So why do we do it? What motivates organizations to take up the challenge? One simple answer is: necessity. All organizations face changes and uncertainty in their environments and added competitive pressures from other actors in the field. As such, organizations need to retain the ability to react to evolving external pressures and differentiate themselves from and out-perform competitors (contingency theory). All organizations need to renew themselves in order to survive in the long run, especially in fast changing environments, thus innovation becomes a 'perpetuum mobile' of organizations and professions. Peter Senge, ${ }^{16}$ in his seminal work 'The fifth discipline: the art and practice of the learning organization', proposes that the key to competitive advantage is the ability to learn. Organizations can only achieve competitive advantage in the long run and significantly improve performance across all dimensions, when they are able to learn. Learning is renewing.

Human beings have an innate ability for learning, the challenge is to get organizations, which are more than a collection of individuals, to learn and what is more, learn at all its levels. The learning organization can reach the results it desires if it can build a set of core capabilities: personal mastery - the ability to clarify goals and focus energies for their achievement; mental models - the ability to scrutinize and update deeply embedded assumptions and thinking patterns; building shared vision - the ability to crystallize a 'picture of the future' which people believe in and share; team learning - the ability to facilitate meaningful dialogue between team 
Ilinca, S., Hamer, S., Botje, D., Espin, J., Veloso Mendes, R., Mueller, J., Wijngaarden, J. van, Vinot, D., Plochg, T. All you need to know about innovation in healthcare: the 10 best reads. International Journal of Healthcare Management: 2012, 5(4), 193-202

members and pooling their individual capacities. The fifth discipline is systems thinking. It pulls together all the other disciplines into a coherent structure and is the lynchpin of Senge's argument. It describes the capacity to represent people and organizations as parts of intricate systems, with multiple interacting parts and interrelated actions. A deeper understanding of complexity and causality is necessary: a snapshot approach is inherently limited and insufficient, as is the conceptualization of causal relations as linear.

But while all professions and organizations will strive for survival, which constitutes a major driver of innovation, it is not the only driver.

Ultimately, health technologies are produced and medical research is undertaken to improve population health, and reduce the burden of morbidity.

Despite the fact that developments in healthcare, fuelled by on-going innovations, have unmistakably contributed to improving population health, this trend of rapid technological change can also lead to undesirable outcomes.

Health technologies are human constructs and a sociological critique of the developments in the field is necessary. Andrew Webster ${ }^{17}$ takes on the challenge and adds a societal perspective to the analysis of the relationship between health innovation and society. His account paints the image of a relation which varies both between different societies and over time, and where the interests of policy makers, pharmaceutical, and health delivery organization can conflict with those of patients. The influence of corporations and market mechanisms in shaping the healthcare system and health innovation processes are considered too strong and might lead to undesired outcomes as the over-medicalization of society, for the sole interest of profits, if not framed and regulated properly. As a result, Webster proposes a more central role for sociologists in the health policy debate, especially as it relates to issues of risk assessment and communication and the evaluation of medical technologies.

\section{WHAT? The innovation process}

But whether they are driven by competitive pressures or a social mandate to improve public health, healthcare organizations who undertake innovation processes are faced with the challenge of bridging the phase of invention with that of full implementation.

This is the innovation process, spanning from the first successful practical application to the internalization of the new technology and its embedding in organizational practices. While the progression has been thought of for decades as being linear and direct, passing through a number of ordered, sequential, and mandatory stages, more recent research has revealed a complex, flexible structure, where numerous factors interact and shape final outcomes. This complexity is one of the reasons why the literature on innovation may seem at times equivocal and not practical. So what is the process through which innovation is created? Akrich et al. ${ }^{18}$ present it as a dynamic adaptation process, with twists and turns along the way. Innovation processes do not follow the all too familiar logistical curves; rather, their hallmarks are complexity and uncertainty, and they 'reveal a multiplicity of heterogeneous and often confused decisions'. ${ }^{18}$ Even if initially the intrinsic qualities of the proposed innovation and the complementarity between the innovation and existing demand (used here in the looser sense of organizations that might benefit 
Ilinca, S., Hamer, S., Botje, D., Espin, J., Veloso Mendes, R., Mueller, J., Wijngaarden, J. van, Vinot, D., Plochg, T. All you need to know about innovation in healthcare: the 10 best reads. International Journal of Healthcare Management: 2012, 5(4), 193-202

from the introduction of the innovation) would seem to have stacked the odds in the favour of a particular technology, there are no guarantees it will ever reach implementation.

Examples of good innovations which were received well initially but failed along the process are numerous.

What was missing was gaining the acceptance and active support of key participants in the process. The level of mobilization necessary to reach innovation adoption can be formidable and it hinges on finding the right actors to support and promote it. The propagation of innovation relies on the links which from between the technology itself and those who interact with it, and its success depends to a large extent on finding the right allies.

The importance of the interaction between the innovation and the shaping forces in the environment is also emphasized in Consoli and Mina's ${ }^{19}$ study on health innovation systems, defined as complex bundles of novel technologies and/or practices.

In this systemic framework, they focus on the dynamic nature of the process, whereby the development and propagation phases of the innovations process are not separable and sequential but entwined. They evolve together and are locked in a twodirectional causal relation, whereby innovation arises from the environment and modifies it through constant feedback loops. In this optic, innovation processes can be imagined to follow a problem-dependent structure: in a particular context, a problem or limitation is identified and a solution is proposed based on available knowledge both at the practical and the academic level and finally, the proposed solution is implemented. This progression relies on the collective accrual of knowledge through the constant interactions between agents across the system (gateways for innovation) for the definition of problems. As a result, the formulation of innovative solutions is largely pathdependent and shaped by the idiosyncrasies of the time and place (pathways to innovation).

Whatever the perspective we wish to take on innovation processes, it is important not to lose sight of the existing variability. Practical experiences have shown, time and again, that not all innovation processes are created equal. As big ideas might turn out to have practically no impact, little ideas can go on to make millions and produce revolutionary change.

To describe this dynamic, Clayton Christensen et al. ${ }^{19}$ has coined the term 'disruptive innovation' - a technological innovation which enters the field, displaces existing practices and technologies, and grows to dominate the market. This does not occur as a single event, but rather as a process of refinement of the innovative technology, which, having entered the field at a lower level of sophistication has evolved to respond to crucial needs and has progressed to being the dominant practice. But while disruptive innovations are hindered by heavily regulated environments, as healthcare is, the author describes the main opportunities in the field: innovative technologies which would allow complex tasks to be performed by less skilled providers and organizational arrangements which allow logistical centralization of healthcare delivery to distributed environments. ${ }^{20}$

\section{HOW? The diffusion of innovation}

Despite the complexity of the process as described above, innovations with strong evidence bases abound in healthcare. However, despite having proven their effectiveness and even after successful implementation in some organizations, 
Ilinca, S., Hamer, S., Botje, D., Espin, J., Veloso Mendes, R., Mueller, J., Wijngaarden, J. van, Vinot, D., Plochg, T. All you need to know about innovation in healthcare: the 10 best reads. International Journal of Healthcare Management: 2012, 5(4), 193-202

numerous innovations fail to spread throughout the field and at times even throughout the adopting organization.

The diffusion of innovation, a process by which innovation is 'communicated through certain channels over time, among the members of a social system ${ }^{1}$ has captured enormous attention from researchers and has traditionally been one of the most widely studied processes in social sciences. ${ }^{20}$ The challenge is to understand how certain innovations and best practices make the leap from novel to mainstream practices and how can managers actively encourage the spread of innovation in their organizations. How does innovation spread in healthcare systems? As it does when it comes to innovation processes, the answer lies with a strong relationship and correct matching between the innovation and its environment. In his review of the research on the topic, Berwick ${ }^{21}$ identifies three main clusters of factors which impact on the speed and breadth of innovation diffusion. The first groups together indicators of the way in which the innovation is perceived, from the expected benefit of adopting the innovation, to compatibility with the core values of the organization, and the flexibility of the innovation itself. Innovations which are simple, lead to measurable and readily observable benefits, have the necessary plasticity to be adaptable to different contexts and match well with the beliefs and needs of adopters will tend to spread faster. Second, the characteristics of the adopters have an important role in the diffusion process. Individuals are different in their propensity for accepting change and their ability to champion it; understanding which individuals in the organizations are likely to react positively to the introduction of an innovation offers the opportunity to leverage their potential.

Finally, a cluster of contextual factors can be defined, which significantly includes the managerial competences of leadership and their ability to adapt their approaches to fit the social context and the innovation at hand.

Denis et al. ${ }^{22}$ also conceptualize the innovation and the adopting system - describing both the involved actors and their interests, values and power relation, as being unescapably linked together in the diffusion process, which represents the mapping of the first on the latter. Despite this interaction the fundamental characteristics of the innovation, which most intimately define its nature, will remain unchanged. This represents the hard core, the immutable part of the innovation. It is complemented by a soft periphery, consisting of the more flexible characteristics of the innovation, which is susceptible to manipulation from the adopters during the implementation process. In consequence, the innovation can be transformed during the adoption process as the involved actors work to align it to their particular mix of interests and values, leading to the creation of multiple possible pathways to adoption. In an encyclopaedic study, Greenhalgh et al. ${ }^{23}$ reaffirm the findings in the studies presented above. Their review draws on an enormous body of literature on innovation diffusion and combines insights from sociology, psychology, epidemiology, political science, organizational theory, and management into a comprehensive conceptual model for the dissemination of innovation in healthcare. Together with the relevance of innovation attributes, contextual antecedents and characteristics of adopters they underline the importance of system readiness for innovation. A number of key conditions need to be in place in order to move health systems into a ready stage; among them the tension for change (innovation is more likely to spread if the status quo is perceived as untenable), support and advocacy (the allies and promoters of the innovation enjoy a strategic placement in the system 
Ilinca, S., Hamer, S., Botje, D., Espin, J., Veloso Mendes, R., Mueller, J., Wijngaarden, J. van, Vinot, D., Plochg, T. All you need to know about innovation in healthcare: the 10 best reads. International Journal of Healthcare Management: 2012, 5(4), 193-202

and the possibility to leverage on it), and capacity to evaluate the innovation (the existence of monitoring and performance evaluation systems for innovation impact favour its dissemination). It is also essential to understand, although less attention has been dedicated to it in the literature, the links which form between these clusters of influential factors and the synergies which can result. To give but one example, innovations which have been linked with potential adopters in their development stage and which, as a result, have been designed with a thorough understanding of the values and meaning they are expected to provide, are likely to have a higher impact and display faster diffusion.

\section{WHO? The actors}

Throughout this paper, whether we were addressing the reasons, the processes, or the diffusion of innovation one argument emerged, over and over, as critical: innovation is ultimately shaped by the participating actors. As the success and spread of innovation is contingent on the results of the interaction between such actors, understanding how their characteristics impact on process becomes a principal concern. So, who are the actors who drive or hinder innovation? In healthcare, they are mainly doctors, nurses, and health technicians; in other words, highly trained professionals.

A high level of professionalism was thought to be positively associated with organizational innovation, with an especially strong impact on process innovations. ${ }^{23}$ More recent research focusing specifically on healthcare organizations contests this finding. Adler and Kwon ${ }^{24}$ argue that while professional groups in healthcare retain a high level of autonomy and as a consequence are able to control the diffusion process, with only minimal influences from third parties, it does not necessarily lead to optimal adoption (more often than not innovations are under- or over-adopted). Professionalized actors are unlikely to accept new practices when directed by managers but are prone to adopting innovation effectively in the presence of professional champions and boundary spanners, which can orient them toward essential knowledge. As a result, in highly professionalized organizations innovations that are supported by professional associations will diffuse faster than those initiated at the administrative or policy levels. Despite these barriers, Adler and Kwon conclude professionals are key facilitators for innovation diffusion and when organizations put in place formal communication channels and strategic controls, they become valuable allies in the innovation process.

Especially, when clinicians are drawn into managerial roles they can become key communicators of change and help reduce friction between professionals and management. ${ }^{24}$ The insulation of professional associations from outside forces and the retention of decision-making power at this level complicates interaction not only with management and government, but also with different professional groups. Ferlie et al. ${ }^{24}$ point out that, in the case of complex innovations, the implementation of which spans across different professional groups, the requirement that they work together during the adoption process can clash with existing differences in professional cultures. This problem is exacerbated in the context of large multiprofessional organizations (e.g.

hospitals, polyclinics) which bring together numerous communities of practice. While professional groups are great repositories of knowledge which diffuses very efficiently between its members, they are generally uni-disciplinary, highly 
Ilinca, S., Hamer, S., Botje, D., Espin, J., Veloso Mendes, R., Mueller, J., Wijngaarden, J. van, Vinot, D., Plochg, T. All you need to know about innovation in healthcare: the 10 best reads. International Journal of Healthcare Management: 2012, 5(4), 193-202

institutionalized, and isolated from neighbouring communities of practice by social, identity, and cognitive boundaries.

Strong professional groups have a documented propensity to block externally oriented sources of change and learning, and knowledge is unlikely to disseminate across these barriers. This leads to the creation of an environment where uniprofessional innovations will tend to spread faster and easier than multi-professional initiatives.

The mismatch can be mitigated by encouraging the formation of relationships across communities of practice and the creation of a shared culture, through the promotion of common values, social interaction, and trust.

\section{DISCUSSION AND CONCLUSION}

We set out, in this analysis, to survey the extensive literature on innovation in healthcare and provide a concise, multi-disciplinary overview which would be accessible to healthcare managers. It proved to be a more complex task than initially expected by virtue of the complexity of the topic, further complicated by the enormous amount of material to review, and the theoretical fragmentation which abounds in the field. Despite these challenges we feel we have, to a large extent, succeeded in reaching our goal of providing a helpful overview of the 10 best reads on innovation.

To begin with, we have created a set of easily understandable categories - why? what? how?, and who? - which despite their simplicity prove very useful in analysing the innovation process throughout its phases. This basic framework can give healthcare managers an accessible and understandable structure to use when considering innovation design and implementation in their organizations. Second, in line with our initial objective, we maintained a focus on multi-disciplinarity and used a broad selection base. While the final choice of the 10 contributions remains subjective and is open to debate, our review bridges many different strands of literature and attempts to give each perspective its right importance. To this end, we included in the list studies which draw heavily on the sociology of profession and complexity science, approaches which have been somewhat overlooked in the past by mainstream researchers in the field. Finally, our analysis contributes to the debate on the role of medical professionals in healthcare management. By analysing the roles different actors play in the innovation process - the who question in our framework - especially as it relates to the role of professionalism, we emphasize the importance of aligning interests and facilitating communication between the two levels. This find suggests that the figure of hybrid managers will become increasingly central in the healthcare innovation arena.

Our study has two main limitations. The most important relates to the language barrier. By reducing our selection pool to contributions written in English, we have artificially reduced the focus of our review. While this bias is likely modest and somewhat mitigated by the multi-national perspectives brought to the analysis by our diverse group, it is worth noting that it leads to a loss of generalizability.

The second limitation lies in the inability to pull together in a consistent framework all the different perspectives represented in the literature.

While attempting to represent an overview as broad as possible, due to the necessity of eliminating incompatibilities, several strands of literature are not exemplified in our list. 
Ilinca, S., Hamer, S., Botje, D., Espin, J., Veloso Mendes, R., Mueller, J., Wijngaarden, J. van, Vinot, D., Plochg, T. All you need to know about innovation in healthcare: the 10 best reads. International Journal of Healthcare Management: 2012, 5(4), 193-202

We conclude by reiterating our belief that healthcare managers who want to encourage innovation within their organizations should ask themselves who wants to innovate what, why, and how. These very simple questions, if properly considered, will prevent them from approaching the innovation processes too narrowly and underestimate the importance each part will have in the process. A broader approach to innovation processes in healthcare organizations would facilitate the understanding of the complex relationships which form between the actors, the nonlinearity of diffusion, and the impact innovations will have on the organization itself and ultimately on society.

\section{ACKNOWLEDGEMENTS}

This article draws on work carried out by the Working Group 4 Innovation of the 7th EU Framework Programme COST Action IS0903 'Enhancing the Role of Medicine in the Management of European Health Systems - Implications for Control, Innovation and User Voice', chaired by Professor Ian Kirkpatrick. The main objective of the action is to increase empirical, theoretical, and policy relevant knowledge about the changing role of medical professionals in the management of healthcare and outcomes of this and possible outcomes. For further information please visit: http://www.dr-in-mgmt.eu

\section{REFERENCES}

1. Stuckler D, McKee M. Commentary: UN high level meeting on non-communicable diseases: an opportunity for whom? BMJ 2011.

2. Anderson $G$. The latest disease burden challenge: people with multiple chronic conditions. In: OECD, Health Reform. Meeting the challenge of ageing and multi-morbidities. Paris: OECD publishing; 2011.

3. Tinetti ME. The retreat from advanced care planning.

JAMA 2012;307(9):915-16.

4. Anessi Pessina E, Cantu E. Whither managerialism in the Italian National Health Service? Int J Health Plann Manage 2006;21:327-55.

5. Glendinning $C$. Breaking down barriers: integrating health and care services for older people in England. Health Policy 2003;65(2):139-51 (Rogers, 2003: 12).

6. Rogers EM. Diffusion of innovations. 5th ed. New York: Free Press, 1995.

7. European Commission. Europe 2020 flagship initiative innovation union. Brussels; 2011.

8. Thompson Klein J. Interdisciplinarity: history, theory, and practice. Wayne State University Press; 1990.

9. Adler M, Ziglio E. Gazing into the oracle: the Delphi method and its application to social policy and public health. Jessica Kingsley Publishers; 1996.

10. Jones J, Hunter D. Qualitative research: consensus methods for medical and health services research.

BMJ, 1995:311(7001):376-80.

11. Pavitt K. Sectoral patterns of technical change: towards a taxonomy and a theory. Res Policy 1984; 13(6):343-73.

12. Arundel $A$, Hollanders $H$. A taxonomy of innovation: how do public sector agencies innovate? Results of the 2010 European Innobarometer survey of public agencies. 2011.

13. Adams R, Tranfield D, Denyer D. A taxonomy of innovation: configuration of attributes in innovations in healthcare. Int J Innov Manag 2011;15(2):359-92.

14. Plochg T, Hamer S. Innovation more than an artefact? Conceptualising the effect of drawing medicine intomanagement.

Int J Healthc Manage 2012. 
Ilinca, S., Hamer, S., Botje, D., Espin, J., Veloso Mendes, R., Mueller, J., Wijngaarden, J. van, Vinot, D., Plochg, T. All you need to know about innovation in healthcare: the 10 best reads. International Journal of Healthcare Management: 2012, 5(4), 193-202

15. Harrower T. Inside reporting: a practical guide to the craft of journalism. MsGraw Hill; 2007.

16. Senge PM. The fifth discipline: the art and practice of the Learning Organization. New York: Currency Doubleday; 1990.

17. Webster A. Health technology and society: a sociological critique. Basingstoke: Palgrave Macmillan; 2007.

18. Akrich M, Callon M, Latour B. The key to success in innovation part I: the art of interessement. Int J Innovation Manage 2002;6(2):207-25.

19. Consoli D, Mina A. An evolutionary perspective on health innovation systems. J Evol Econ 2009;19(2): 297-319.

20. Christensen C, Grossman J, Hwang J. The innovator's prescription: a disruptive solution for health care.

McGraw-Hill Professional; 2009.

21. Berwick DM. Disseminating innovations in health care. JAMA 2003;289(15):1969-75.

22. Denis JL, Hebert Y, Langley A, Lozeau D, Trottier LH.

Explaining diffusion patterns for complex health care innovations. Health Care Manage Rev 2002;27(3): 60-73.

23. Greenhalgh T, Robert G, Macfarlane F, Bate P, Kyriakidou O. Diffusion of innovations in service organizations: systematic review and recommendations.

Milbank Q 2004;82(4):581-629.

24. Adler PS, Kwon S. Unreliable allies: the diffusion of innovation among professionals. 2009. Available from: SSRN. http://ssrn.com/abstract=1329141 25. Ferlie E, Fitzgerald L, Wood M, Hawkins C. The nonspread of innovations: the mediating role of professionals. Acad Manage J 2005;48(1):117-34.

26. Christensen $C$. The innovator's dilemma: when new technologies cause great firms to fail. Cambridge, MA: Harvard Business Press; 1997.

27. Mahajan V, Peterson A. Models for innovation diffusion, Issue 48, SAGE University Papers Series: Quantitative Applications in the Social Sciences.

SAGE; 1985.

28. Damanpour F. Organizational innovation: a metaanalysis of effects of determinants and moderators.

Acad Manage J 1991;34(3):555-90.

29. Sheaff R, Rogers A, Pickard S, Marshall M, Campbell S, Sibbald B, et al. A subtle governance: 'soft' medical leadership in English primary care. Sociol Health IIIn 2003;25(5):408-28.

Ilinca et al. - The 10 best reads 202 International 
Ilinca, S., Hamer, S., Botje, D., Espin, J., Veloso Mendes, R., Mueller, J., Wijngaarden, J. van, Vinot, D., Plochg, T. All you need to know about innovation in healthcare: the 10 best reads. International Journal of Healthcare Management: 2012, 5(4), 193-202

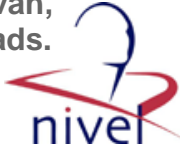

TABLES:

Table 1: The ten best reads on innovation in healthcare

\begin{tabular}{|c|c|c|c|c|}
\hline & $\begin{array}{l}10 \text { papers on } \\
\text { innovation }\end{array}$ & Main contribution to the innovation literature & $\begin{array}{l}\text { Theoretical } \\
\text { perspective(s) }\end{array}$ & Additional value \\
\hline \multirow[t]{2}{*}{$\begin{array}{l}\text { WHY? The } \\
\text { purpose }\end{array}$} & Senge $^{16}$ & $\begin{array}{l}\text { Under conditions of rapid change and uncertainty } \\
\text { innovation arises from the need of organizations to } \\
\text { be flexible and adaptive, i.e. have a high capacity for } \\
\text { learning. Successful organizations must master both } \\
\text { 'adaptive (survival) learning' in order to endure and } \\
\text { 'generative' learning in order to foster creativity }\end{array}$ & $\begin{array}{l}\text { Organizational } \\
\text { learning }\end{array}$ & $\begin{array}{l}\text { The dimension that distinguishes 'the learning } \\
\text { organization' from more traditional organizations } \\
\text { is the mastery of five basic disciplines: systems } \\
\text { thinking; personal mastery; mental models; } \\
\text { building shared vision; and team learning }\end{array}$ \\
\hline & Webster $^{17}$ & $\begin{array}{l}\text { Innovations in healthcare have contributed to } \\
\text { improving the general health of the population. } \\
\text { However, some innovations arise under the pressure } \\
\text { of market mechanisms and might conflict with the } \\
\text { interests of society. A balanced understanding of the } \\
\text { benefits and costs of the innovation process must } \\
\text { take a societal perspective }\end{array}$ & $\begin{array}{l}\text { Sociological } \\
\text { perspective }\end{array}$ & $\begin{array}{l}\text { Health innovations are promoted to improve } \\
\text { effectiveness and efficiency of health services, but } \\
\text { often increase the medicalization of human life. } \\
\text { Discusses the different types of governance models } \\
\text { in healthcare and how governance relates to ethics } \\
\text { in medicine and healthcare }\end{array}$ \\
\hline \multirow[t]{3}{*}{$\begin{array}{l}\text { WHAT? } \\
\text { The } \\
\text { process }\end{array}$} & Akrich et al. ${ }^{18}$ & $\begin{array}{l}\text { The process of innovation in healthcare has wrongly } \\
\text { been considered a linear adoption process. Rather, it } \\
\text { is a dynamic process of adaptation, locking different } \\
\text { actors in adversarial or cooperative interactions }\end{array}$ & $\begin{array}{l}\text { Evolutionary } \\
\text { perspective }\end{array}$ & $\begin{array}{l}\text { Offers a good introduction in sociotechnical theory } \\
\text { and offers insight on the distinction between } \\
\text { innovation and invention. Proposes an alternative } \\
\text { to the classical diffusion model in the form of the } \\
\text { interessement model }\end{array}$ \\
\hline & $\begin{array}{l}\text { Consoli and } \\
\text { Mina }^{19}\end{array}$ & $\begin{array}{l}\text { Innovation is a dynamic non-deterministic process } \\
\text { arising from complex interactions between various } \\
\text { actors, constrained by system configurations. It } \\
\text { spans multiple dimensions, among which time, } \\
\text { specialized competences and scientific knowledge }\end{array}$ & $\begin{array}{l}\text { Systems thinking - } \\
\text { evolutionary } \\
\text { perspective }\end{array}$ & $\begin{array}{l}\text { Main drivers of innovation systems: gateways } \\
\text { (interactions among agents within the boundaries } \\
\text { of institutions) and pathways (trajectories of } \\
\text { change) }\end{array}$ \\
\hline & $\begin{array}{l}\text { Christensen } \\
\text { et al. }{ }^{20}\end{array}$ & $\begin{array}{l}\text { While some innovations make but a splash in the field, } \\
\text { others go on to produce revolutionary changes. } \\
\text { These are disruptive innovation, which start with } \\
\text { small applications of a new technology and } \\
\text { eventually go on to displace the existing value } \\
\text { network and market }\end{array}$ & $\begin{array}{l}\text { Institutional theory - } \\
\text { systems thinking }\end{array}$ & $\begin{array}{l}\text { Three crucial factors for disruptive innovations are } \\
\text { identified: technological enablers, business model } \\
\text { innovation, and the value network. Discusses the } \\
\text { need for systemic integration in healthcare }\end{array}$ \\
\hline $\begin{array}{l}\text { HOW? The } \\
\text { spread }\end{array}$ & Berwick $^{21}$ & $\begin{array}{l}\text { 'In healthcare, invention is hard, but dissemination is } \\
\text { even harder' and it results in the deepening of the } \\
\text { gap between knowledge and practice. Innovation } \\
\text { spread crucially hinges on how the innovation is } \\
\text { perceived, the characteristics of adopters, and a } \\
\text { series of contextual factors }\end{array}$ & $\begin{array}{l}\text { Diffusion of } \\
\text { innovation }\end{array}$ & $\begin{array}{l}\text { Provides a list of seven recommendations for } \\
\text { healthcare executives who want to accelerate the } \\
\text { rate of diffusion of innovations: find sound } \\
\text { innovations; find and support innovators; invest in } \\
\text { early adopters; make early adopter activity } \\
\text { observable; trust and enable reinvention; create } \\
\text { slack for change and lead by example }\end{array}$ \\
\hline
\end{tabular}

Table 1: Continued

\begin{tabular}{|c|c|c|c|c|}
\hline & $\begin{array}{l}10 \text { papers on } \\
\text { innovation }\end{array}$ & Main contribution to the innovation literature & $\begin{array}{c}\text { Theoretical } \\
\text { perspective(s) }\end{array}$ & Additional value \\
\hline \multirow{4}{*}{$\begin{array}{l}\text { WHO? The } \\
\text { actors }\end{array}$} & Denis et al. ${ }^{22}$ & $\begin{array}{l}\text { Innovations consist of a hard core (well-defined and } \\
\text { relatively fixed) and a soft periphery (flexible and } \\
\text { easier to manipulate by the adopting system). As the } \\
\text { diffusion process represents the mapping of } \\
\text { innovations on the adopting system (key actors; } \\
\text { interests and power distribution) multiple adoption } \\
\text { pathways can arise from the reshaping of the soft } \\
\text { periphery }\end{array}$ & $\begin{array}{l}\text { Diffusion of } \\
\text { innovation }\end{array}$ & $\begin{array}{l}\text { Builds on concepts stated in Latour's actor-network } \\
\text { theory. Identifies two diffusion patterns: one driven } \\
\text { by clinicians and their interest in providing state of } \\
\text { the art care, another driven by managers and their } \\
\text { focus on procedural and structural efficiency }\end{array}$ \\
\hline & $\begin{array}{l}\text { Greenhalgh } \\
\text { et al. } .^{23}\end{array}$ & $\begin{array}{l}\text { Innovation diffusion depends on: the characteristics of } \\
\text { the innovation (e.g. relative advantage of its } \\
\text { effectiveness, compatibility with existing norms, and } \\
\text { beliefs and potential for reinvention); the } \\
\text { characteristics of individuals involved in the } \\
\text { adoption process; system antecedents and readiness; } \\
\text { and inter-organizational networks }\end{array}$ & $\begin{array}{l}\text { Diffusion of } \\
\text { innovation }\end{array}$ & $\begin{array}{l}\text { Synthesizes an enormous body of literature on } \\
\text { innovation diffusion, representing various research } \\
\text { traditions, in a comprehensive framework - the } \\
\text { 'conceptual model for considering the determinants } \\
\text { of diffusion, dissemination, and implementation of } \\
\text { innovations' }\end{array}$ \\
\hline & $\begin{array}{c}\text { Adler and } \\
\text { Kwon }^{24}\end{array}$ & $\begin{array}{l}\text { The level of diffusion (speed, scope, and depth of the } \\
\text { innovation adoption process) is linked to the level of } \\
\text { professionalization of involved actors In highly } \\
\text { professional environments - as healthcare is - the } \\
\text { influence of third-party actors is weak and } \\
\text { normative considerations shape innovation } \\
\text { diffusion }\end{array}$ & $\begin{array}{l}\text { Sociology of } \\
\text { professions }\end{array}$ & $\begin{array}{l}\text { Discusses under- and over-utilization and the socially } \\
\text { optimal level of diffusion. The diffusion of } \\
\text { innovation in professional organizations depends } \\
\text { on strategic control, strong network ties, acquiring } \\
\text { managerial skills, and well-designed information } \\
\text { systems }\end{array}$ \\
\hline & Ferlie et al..$^{25}$ & $\begin{array}{l}\text { Uni-professional innovations tend to spread faster and } \\
\text { easier than multi-professional initiatives. Intra- and } \\
\text { inter-professional boundaries (both social and } \\
\text { cognitive) act as barriers to diffusion and retard } \\
\text { innovation spread }\end{array}$ & $\begin{array}{l}\text { Sociology of } \\
\text { professions }\end{array}$ & $\begin{array}{l}\text { Strong professional groups show a propensity to } \\
\text { block externally oriented sources of change and } \\
\text { learning }\end{array}$ \\
\hline
\end{tabular}

